\title{
ANDES

\section{Respuesta Carta a Editor titulada: Reacciones de hipersensibilidad a asparaginasa}

\author{
Response to the letter of editor entitled: Asparaginase hypersensitivity reactions
}

Pilar Ovalle B. ${ }^{\mathrm{a}, \mathrm{c}}$, Manuel Azócar M. ${ }^{\mathrm{b}, \mathrm{d}}$, Carolina Nicklas D. ${ }^{\mathrm{b}}$, Milena Villarroel C. ${ }^{\mathrm{b}}$, Jorge Morales V. ${ }^{\mathrm{b}, \mathrm{d}}$

${ }^{a}$ Complejo Asistencial Dr. Sótero del Río. Santiago, Chile

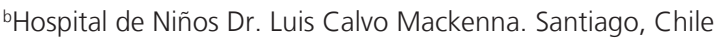

‘División de Pediatría, Pontificia Universidad Católica de Chile

dFarmacéutico Clínico

\section{Sr. Editor,}

Hemos leído las observaciones hechas a nuestro artículo "Reacciones de hipersensibilidad (RHS) asociadas al uso de asparaginasa (ASP) en niños con leucemia linfoblástica aguda (LLA)"'. La ASP es uno de los medicamentos fundamentales en la quimioterapia de la LLA pediátrica. Su origen bacteriano favorece la formación de anticuerpos y el desarrollo de RHS, lo cual tiene importancia no sólo por la repercusión aguda de la RHS, sino porque los anticuerpos desarrollados contra la ASP también la inactivan, llevándola a perder su efecto antileucémico si los niveles de actividad de ASP (activ-ASP) descienden bajo 0,1 UI/ml de suero. Se ha observado una relación inversa entre los títulos de anticuerpos y la activ-ASP y que hasta un 30\% de los pacientes presenta "inactivación silente" de ASP, mediada por anticuerpos ${ }^{2}$. Los protocolos internacionales de LLA indican cambiar el tipo de ASP ante RHS grado 2 o mayor según Common Terminology Criteria for Adverse Events (CTCAE) o suspenderla en forma definitiva si no existe otra formulación disponible. Esto tiene repercusión clínica, ya que su suspensión se ha relacionado a una menor sobrevida libre de eventos (SLE). Para las RHS grado 1, los consensos de expertos recomiendan medir la activ-ASP para evaluar la efectividad de mantener la formulación utilizada ${ }^{3}$.

La mayoría de las RHS a ASP son unifásicas y se producen durante los primeros 20 minutos de la infusión, suceso también observado en nuestro estudio, lo que sugiere que corresponden a reacciones tipo 1, mediadas por IgE. Sin embargo, a diferencia de otras RHS, en los reportes de reacciones a ASP también se han encontrado reacciones tipo alérgicas, con síntomas similares, pero no mediadas por anticuerpos, e inactivación de la ASP incluso en reacciones grado $1^{3}$.

Desarrollamos una adaptación de CTCAE 5.0 porque los reportes de RHS demuestran que muchos pacientes desarrollan broncoespasmo y angioedema sin hipotensión, con rápida respuesta al manejo sintomático y que la hipotensión ayuda a diferenciar a los que se beneficiarán de un manejo directo con epinefrina ${ }^{3}$. Coincidimos en que el manejo de toda RHS comienza por la retirada del agente causal y por eso, la primera medida en todos nuestros pacientes, al igual que en el algoritmo, fue la suspensión de la infusión

Correspondencia:

Pilar Ovalle B.

pilarovalleb@gmail.com 
de ASP, siendo suficiente para la resolución de la RHS en 2 de ellos. La tabla 3 muestra el nivel de tratamiento escalonado al que respondieron los pacientes, lo que pudiera no quedar claro por la forma de presentar los datos. Casi todas las series de RHS a ASP y recomendaciones de expertos mencionan el manejo sintomático con antihistamínicos y corticoides como medidas terapéuticas efectivas, que llevan al cese de la mayoría de las reacciones. Considerando, sin embargo, que las recomendaciones de manejo de anafilaxias incluyen la epinefrina intramuscular como primera línea, nosotros lo hemos propuesto para todas las RHS grado $4 \mathrm{y}$, como alternativa, en las RHS grado 3, lo que implica un cambio en la conducta tradicional de muchos equipos oncológicos.

Hasta la fecha hay escasos reportes de desensibilización a ASP. De los mencionados en su carta, sólo 2 incluyen la medición de activ-ASP, examen que finalmente nos indicará si el protocolo ha logrado el efecto terapéutico, independiente de la seguridad clínica del procedimiento. Verma demostró que 8 de los 10 pacientes incluidos lograron niveles de activ-ASP adecuados entre el día 4 y 7, y que sólo 7 mantenían un nivel terapéutico entre los días 10 y $14^{4}$. Por otro lado, Swanson observó que los títulos de anticuerpos se podrían relacionar con la posibilidad de una desensibilización exitosa y que los 2 (de 7) que no lograron una activ-ASP terapéutica tenían títulos de anticuerpos más elevados ${ }^{5}$. Se requieren estudios prospectivos con un mayor número de pacientes para evaluar la efectividad de la desensibilización a ASP, que consideren tanto los niveles de activ-ASP como el pronóstico de SLE y la sobrevida global de los pacientes.

Todos nuestros pacientes están incluidos en estrictos protocolos internacionales que indican cambiar el tipo de ASP si el paciente presenta una RHS y retirarla del tratamiento si no hay otra formulación alternativa. No podemos por tanto recomendar como práctica habitual la desensibilización ante RHS más graves en países que no cuentan con medición de activ-ASP ni de anticuerpos anti-ASP, como es el caso de Chile y otros países de Latinoamérica, más aún si consideramos que una de nuestras pacientes falleció a causa de una RHS a PEG-ASP. No obstante, queda a criterio de cada grupo clínico la factibilidad de utilizar protocolos de desensibilización a ASP en sus pacientes.

\section{Referencias}

1. Ovalle P, Azócar M, Nicklas C, Villarroel M, Morales J. Reacciones de hipersensibilidad asociadas al uso de asparaginasa en niños con leucemia linfoblástica aguda. Andes pediatr 2021;92(2):182-92.

2. Willer A, Gerss J, König T, et al. AntiEscherichia coli asparaginase antibody levels determine the activity of secondline treatment with pegylated $E$. coli asparaginase: a retrospective analysis within the ALL-BFM trials. Blood 2011;118(22):5774-82.

3. Van der Sluis IM, Vrooman LM, Pieters R, et al. Consensus expert recommendations for identification and management of asparaginase hypersensitivity and silent inactivation. Haematologica 2016;101(3):279-85.

4. Verma A, Chen K, Bender C, Gorney N, Leonard W, Barnette P. PEGylated E. coli asparaginase desensitization: an effective and feasible option for pediatric patients with acute lymphoblastic leukemia who have developed hypersensitivity to pegaspargase in the absence of asparaginase Erwinia chrysanthemi availability. Pediatr Hematol Oncol 2019;36(5):277-86.

5. Swanson HD, Panetta JC, Barker PJ, et al. Predicting success of desensitization after pegaspargase allergy. Blood 2020;135(1):71-5 